\title{
Intensity of estrus following an estradiol-progesterone-based ovulation synchronization protocol influences fertility outcomes
}

\author{
A. M. L. Madureira, ${ }^{1}$ L. B. Polsky, ${ }^{1}$ T. A. Burnett, ${ }^{1}$ B. F. Silper, ${ }^{1}$ S. Soriano, ${ }^{2}$ A. F. Sica, ${ }^{2}$ K. G. Pohler, ${ }^{3}$ \\ J. L. M. Vasconcelos, ${ }^{4}$ and R. L. A. Cerri ${ }^{1 *}$ \\ ${ }^{1}$ Applied Animal Biology, Faculty of Land and Food Systems, University of British Columbia, Vancouver, BC, Canada V6T 1 Z4 \\ ${ }^{2}$ Colorado Farm, Box 286, Araras, Brazil 13600-970 \\ ${ }^{3}$ Department of Animal Science, University of Tennessee, Knoxville 37920 \\ ${ }^{4}$ Department of Animal Production, São Paulo State University, Botucatu, Brazil 18168-000
}

\section{ABSTRACT}

The objective of this study was to examine the association between increased physical activity at the moment of timed artificial insemination (AI), detected by an automated activity monitor (AAM), and fertility outcomes. This paper also investigated factors affecting estrous expression in general. A total of 1,411 AI events from 1,040 lactating Holstein cows were recorded, averaging $1.3 \pm 0.6$ ( \pm standard deviation) events per cow. Activity (measured as steps/h) was monitored continuously by a leg-mounted AAM located on the rear leg of the cow. Ovulation was synchronized by a timed AI protocol based on estradiol and progesterone. Ovarian ultrasonography was performed in all cows on $\mathrm{d}-11(\mathrm{AI}=\mathrm{d} 0)$ and in a subset of cows on $\mathrm{d} 0(\mathrm{n}$ $=588)$ and $\mathrm{d} 7(\mathrm{n}=819)$ to determine the presence of a corpus luteum and follicles. The body condition score ( 1 to 5 scale) was assessed on d 0 and a blood sample was collected for progesterone measurement on d 7. Using the AAM, an estrus event was determined when the relative increase (RI) in physical activity of the cow exceeded $100 \%$ of the baseline activity. The physical activity was classified as strong RI $(\geq 300 \%$ RI), moderate RI (100-300\% RI), or no estrus $(<100 \%$ RI). Milk production was measured daily and averaged between $\mathrm{d}-11$ and 0 . Pregnancy was diagnosed at 32 and $60 \mathrm{~d}$ post-AI and pregnancy losses were calculated. The mean RI at estrus was $328.3 \pm 132.1 \%$. Cows with strong RI had greater pregnancy per AI than those with moderate RI and those that did not express estrus (35.1 vs. 27.3 vs. $6.2 \%$ ). When including only cows that successfully ovulated after timed AI, those that displayed strong intensity RI still had greater pregnancy per AI than those with moderate intensity RI or those that did not express estrus (45.1 vs. 34.8 vs. $6.2 \%$ ).

Received May 29, 2018.

Accepted November 28, 2018.

*Corresponding author: ronaldo.cerri@ubc.ca
Cows expressing strong RI at timed AI had greater ovulation rates compared with moderate RI and cows that did not express estrus (94.9 vs. 88.2 vs. $49.5 \%$ ). Furthermore, pregnancy losses were reduced in cows with strong RI compared with cows expressing moderate RI (13.9 vs. $21.7 \%)$. Cows with a strong RI at estrus were more likely to have a corpus luteum at the beginning of the protocol and had greater concentration of progesterone $7 \mathrm{~d}$ post-AI. Multiparous cows expressed lower RI compared with primiparous cows. Cows with lower body condition score tended to have decreased RI at estrus. No correlation between estrous expression and pre-ovulatory follicle diameter was observed. Also, no correlation was observed between milk production at $\mathrm{AI}$ and RI. In conclusion, strong intensity RI of estrus events at timed AI was associated with improved ovulation rates and pregnancy per AI, and reduced pregnancy losses. These results provide further evidence that measurements of estrous expression can be used to predict fertility at the time of AI and possibly be used as a tool to assist decision making strategies of reproduction programs.

Key words: automated activity monitor, estrus, pregnancy per artificial insemination, pregnancy loss

\section{INTRODUCTION}

Detection of estrus is crucial for a successful reproductive program. Historically, standing to be mounted has been the gold standard for visual detection of estrus, but the frequency of standing behavior (Lopez et al., 2004) as well as the proportion of cows that display estrus (Dobson et al., 2008) have decreased over the decades. This trend has been particularly noted in high-producing dairy cows (Lopez et al., 2004; Rivera et al., 2010). Increased physical activity is considered a secondary feature of estrous expression in dairy cattle, but has been used by automated activity monitors (AAM) to reliably identify cows in estrus (Roelofs et al., 2010). 
Increases in physical activity have been associated with improvement in pregnancy per AI of dairy cows (Madureira et al., 2015; Polsky et al., 2017; Burnett et al., 2018). The intensity of estrous expression, as well as fertility, is affected by BCS, parity, stage of lactation, and health (Madureira et al., 2015; Burnett et al., 2017; Silper et al., 2017). Nonetheless, even when accounting for such factors, estrus detection and expression has consistently affected pregnancy per AI (López-Gatius et al., 2005; Madureira et al., 2015; Pereira et al., 2015; Burnett et al., 2017; Silper et al., 2017). Synchronization of ovulation protocols has been used as an alternative to achieve successful reproductive goals as they are able to increase pregnancy rates by improving submission rates to AI without depending on estrus detection (Pursley et al., 1995; Chebel et al., 2010). Recent studies have compared different combinations of timed AI protocols and estrus detection using AAM (Neves et al., 2012; Burnett et al., 2017; Denis-Robichaud et al., 2018b), and results suggested that in North American herds it is possible to maintain comparable reproductive efficiency between estrus-detection-based reproductive programs and those that rely heavily on timed AI. Some recent studies have also reported the effect of estrous expression on fertility focused on spontaneous estrus events but did not test for the effect of estrous expression from timed AI protocols. This question is particularly important in protocols using estrogens to induce ovulation because the majority of the cows express estrus before AI (Cerri et al., 2004; Pereira et al., 2015) as opposed to protocols using a GnRH analog (Stevenson and Phatak, 2005). The occurrence of estrus at AI, using tail chalk and tail head patch, in a timed AI protocol was associated with a reduction in pregnancy loss in dairy cows (Pereira et al., 2014, 2015). Furthermore, Pereira et al. (2015) reported that the reduction in pregnancy loss in cows that expressed estrus at AI occurred regardless of the diameter of the pre-ovulatory follicle. Davoodi et al. (2016) reported that the occurrence of estrus at AI in beef cattle induced changes in gene expression in the endometrium and conceptus that are associated with preimplantation success. It is unclear, however, if the intensity of estrus, and not only the expression of it, after such synchronization protocols also alters fertility outcomes as observed in spontaneous estrus events.

This study aimed at evaluating the association between the intensity of estrous expression, captured by an AAM, and outcomes related to fertility such as ovulation rate, pregnancy per AI, and pregnancy loss, and concentration of progesterone $7 \mathrm{~d}$ after AI. Moreover, it was our objective to determine if BCS, parity, milk production, and ovarian structures were associated with intensity of estrus and fertility. We hypothesized that cows displaying more intense estrus would have increased pregnancy per AI, decreased pregnancy loss and ovulation failures, and greater progesterone concentration after AI.

\section{MATERIALS AND METHODS}

This experiment was conducted at a commercial farm in São Paulo State, Brazil $\left(22^{\circ} 21^{\prime} 25^{\prime \prime}\right.$ S; $47^{\circ} 23^{\prime} 03^{\prime \prime}$ W). The University of British Columbia Animal Care protocol related to the current study was A14-0290. The practices outlined in the Guide for the Care and Use of Agricultural Animals in Agricultural Research and Teaching (FASS, 1999) were also used for the approval of all experimental procedures as part of the local requirements.

\section{Animals, Housing, and Management}

Lactating Holstein cows ( $\mathrm{n}=1,040)$ were enrolled into the study during the first week postpartum with the placement of an AAM to the back limb of the animal. The experimental herd had an average 305-d mature equivalent milk yield of $11,438 \mathrm{~kg} / \mathrm{cow}$ with an average of approximately 1,700 lactating dairy Holstein cows.

This experiment was an observational cohort study. Cows were housed in a cross-ventilated freestall barn in groups of 300 animals. The barn had grooved concrete floors and 2 rows of deep sand-bedded stalls. Milking was performed 3 times daily (at approximately 0500, 1300, and $2100 \mathrm{~h}$ ). Cows were fed a TMR thrice daily. The TMR was formulated to meet or exceed the requirements of a lactating Holstein cow producing 40 $\mathrm{kg} / \mathrm{d}$ of $3.5 \%$ FCM (NRC, 2001). Water and TMR were available for ad libitum intake.

\section{Automated Activity Monitors}

Cows were monitored continuously by one AAM, a leg-mounted pedometer (AfiPedometer Plus Tag, AfiMilk, Kibbutz Afikim, Israel). The pedometer sensor was attached to the right back limb above the distal expansion of the metacarpal bone of each cow on the day of their first calving and remained on the animals throughout their entire time within the herd.

The activity data (steps/h) were recorded in 2 -h increments and were retrieved 3 times daily (every $8 \mathrm{~h}$ ) by an electronic scanner at the entrance of the milking parlor. Using the data from the AAM, the relative increase (RI) in walking activity was calculated by determining the change in activity on $\mathrm{d}-1$ and 0 , relative to timed AI, in comparison to a baseline cal- 
culated specifically for each cow. The following formula was used: [(steps/h at estrus - steps/h at baseline)/ steps $/ \mathrm{h}$ at baseline] $\times 100$. The steps per hour at estrus were defined as the greatest steps per hour from the 8 $\mathrm{h}$-session with the greatest number of steps among all sessions on $\mathrm{d}-1$ or 0 relative to timed AI. Baseline steps per hour represented the average steps per hour from the $7 \mathrm{~d}$ before AI. Cows were only considered to be in estrus if the RI on $d-1$ or 0 exceeded $100 \%$. Only animals that exceeded a RI of $100 \%$ were considered as expressing estrus at timed AI, thus not associated with an alert event from the AAM.

\section{Synchronization Protocol, Blood Sampling, and Analysis of Progesterone}

During the experimental period, cows were enrolled onto an ovulation synchronization protocol based on progesterone and estradiol for first AI postpartum, then again following a negative pregnancy diagnosis. Timed AI was performed using commercially frozen-thawed semen by the same 2 trained technicians. The synchronization protocol used was as follows: an intravaginal progesterone implant of $1.9 \mathrm{~g}$ of progesterone (CIDR, Zoetis, São Paulo, Brazil), a 2.0-mg (i.m.) injection of estradiol benzoate (2.0 mL of Gonadiol, Zoetis), and a $100-\mu \mathrm{g}$ (i.m.) injection of gonadorelin diacetate (GnRH, $2.0 \mathrm{~mL}$ of Cystorelin, Merial, São Paulo, Brazil) on d -11 ; a 25-mg (i.m.) injection of dinoprost tromethamine (PGF, $5.0 \mathrm{~mL}$ of Lutalyse, Zoetis on $\mathrm{d}-4$ and $-2)$; the CIDR was withdrawn on $\mathrm{d}-2$ and a 1.0-mg (i.m.) injection of estradiol cypionate $(0.5 \mathrm{~mL}$, ECP, Zoetis) was administered, and timed AI occurred on d 0, as described by Pereira et al. (2015) and detailed in Figure 1.

Ovaries of all cows were examined by ultrasonography at $d-11$ (presence or absence of corpus luteum), and a subset of cows were examined on d 0 (assessment of 2 largest follicles; $\mathrm{n}=588$ ) and on $\mathrm{d} 7$ (presence or absence of a corpus luteum to confirm ovulation; $\mathrm{n}=$ 819). Pregnancy diagnosis was carried out via ultra- sonography on d 32 and 60 after timed AI, and cows were considered pregnant when a viable embryo was found. Pregnancy per AI was calculated by dividing the number of cows that were pregnant on d 32 post-AI by the number of animals enrolled into the timed AI protocol. The pregnancy loss was calculated by dividing the number of animals that lost gestation between d 32 and 60 post-AI by the number of animals pregnant at $\mathrm{d} 32$.

The BCS ( 1 to 5 scale at 0.25 increments; Edmonson et al., 1989) was recorded at timed AI. Milk production was recorded at each milking (AfiLite, Kibbutz Afikim, Israel). Milk production was measured daily between $\mathrm{d}$ -11 and 0 of the experiment, and the average daily milk production during this period was used for analysis.

All cows examined at $\mathrm{d} 7$ after AI had a blood sample collected, for progesterone analysis, from the coccygeal vein into commercial blood collection tubes (BD Vacutainer Serum Tubes, $10 \mathrm{~mL}$, Becton Dickinson, Franklin Lakes, NJ) and were placed immediately on ice. Samples were then centrifuged at $3,000 \times g$ at $4^{\circ} \mathrm{C}$ for $30 \mathrm{~min}$ for serum collection, and stored at $-20^{\circ} \mathrm{C}$. Serum progesterone concentrations were analyzed using a chemiluminescent enzyme immunoassay (Immulite 1000, Siemens Medical Solutions Diagnostics, Los Angeles, CA) as previously validated (Martin et al., 2007; Reis et al., 2015). The intra- and interassay coefficients of variation were 5.1 and $5.2 \%$, respectively. The minimum detectable concentration was $0.1 \mathrm{ng} / \mathrm{mL}$ of progesterone.

\section{Statistical Analyses}

Distributions and normality tests were obtained using the Univariate procedure in the SAS software, version 9.4 (SAS Institute Inc., Cary, NC). Normality was visually assessed and confirmed by the KolmogorovSmirnov method. Any variable found to not be normal was either transformed or categorized into class variables. Class variables used for analyses are described below. Parity was divided as cows in first lactation and

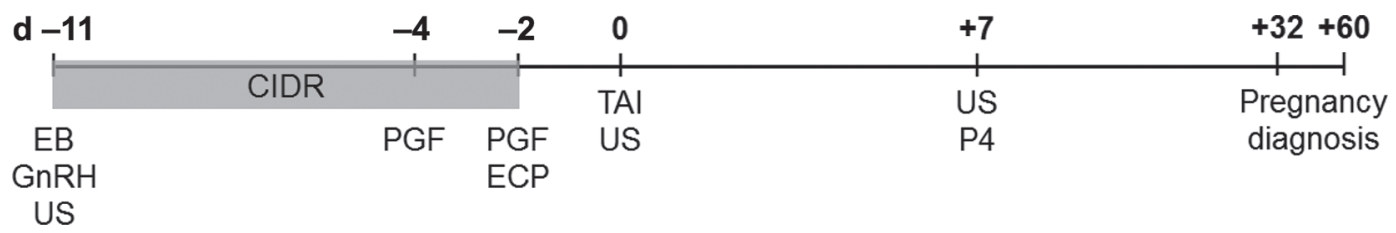

Figure 1. Experimental ovulation synchronization protocol. EB = estradiol benzoate, 2 mg, Gonadiol (Zoetis, São Paulo, Brazil); GnRH =

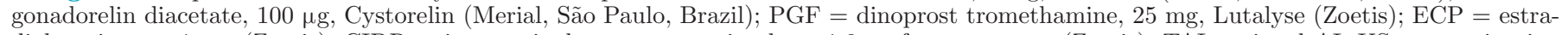
diol cypionate, $1 \mathrm{mg}$ (Zoetis); CIDR = intravaginal progesterone implant, $1.9 \mathrm{~g}$ of progesterone (Zoetis); TAI = timed AI; US = examination

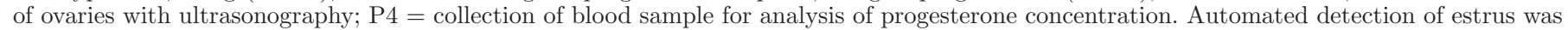
done with Afimilk Pedometer Plus Tags and AfiFarm software (Afimilk, Kibbutz Afikim, Israel). 
second lactation or higher (primiparous vs. multiparous). The BCS categories were low $(<2.75)$, moderate $(2.75-3.00)$, and high $(\geq 3.25)$. Lactation stage at timed AI was classified as early lactation $(\leq 72$ DIM), midlactation ( 73 to $170 \mathrm{DIM})$, and late lactation $(\geq 171$ DIM). Milk production was classified into quartiles ( $\leq 37.5,37.6$ to $44.7,44.8$ to 52.1 , and $\geq 52.2 \mathrm{~kg} / \mathrm{d}$ ). Physical activity of estrus episodes from the AAM was categorized as no estrus $(<100 \% \mathrm{RI})$, moderate (100-299\% RI), and strong ( $\geq 300 \% \mathrm{RI})$. The receiver operating characteristic analysis using MedCalc version 11.1.0.0 (MedCalc software, Mariakerke, Belgium) was performed to determine the critical value of RI that best predicted pregnancy per AI based on sensitivity and specificity, thus separating moderate and strong physical activity. The receiver operating characteristic curve analysis plots the sensitivity against the false positive fraction (1 - specificity) to detect the best combination of sensitivity and specificity for pregnancy per AI.

The correlations between physiological measurements (BCS, diameter of pre-ovulatory follicle, serum progesterone concentration, DIM, and milk production) and automated activity measurements (RI in physical activity) were determined by Pearson correlation using the Corr procedure of SAS. Relative increase in physical activity was used as a continuous dependent variable assessed with ANOVA using the GLIMMIX procedure with AI event as the experimental unit and cow as a random effect. Parity, BCS, milk production, DIM, dominant follicle diameter and corpus luteum presence at $\mathrm{d}-11$ were used as independent variables. Following the same model, dominant follicle diameter was tested as a continuous dependent variable against the fixed effects of parity, BCS, milk production, DIM, $\mathrm{RI}$ in physical activity, and corpus luteum presence at $\mathrm{d}$ -11 . The pregnancy per AI, pregnancy loss, and ovulation failure were binomial dependent variables assessed using the same model. The AI event was again used as the experimental unit and cow as the random effect. Only variables with a $P$-value $<0.15$ were maintained in the final model. Differences with $P \leq 0.05$ were considered significant and those between $0.05>P \leq 0.10$ were designated as a tendency.

\section{RESULTS}

\section{Animals and Number of Events}

A total of 1,411 timed AI events from 1,040 cows were recorded, resulting in $1.3 \pm 0.6$ events per animal. Cows were on average $137 \pm 93$ DIM at the time of data collection. In total, 40.8 and $59.2 \%$ of cows enrolled were primiparous and multiparous, respectively. Of the total inseminations performed, $52 \%$ were first, $16 \%$ second, and $32 \%$ were third AI or greater.

\section{Estrous Expression at Timed Al}

The mean RI at estrus was $328.29 \pm 132.08 \%$. Parity influenced estrous expression, as multiparous cows expressed lower RI at peak of estrus expression preceding the moment of AI $(P<0.01)$ compared with primiparous cows (Table 1 ). Body condition score at timed AI tended to affect RI ( $P=0.10$; Table 1$)$, as cows with lower BCS tended to have lower estrous expression than those with moderate or high BCS. An interaction was observed between parity and BCS $(P<0.04)$, where multiparous cows with low BCS had lower RI than all other parity and BCS combinations (multiparous: low $\mathrm{BCS}=263.1 \pm 19.7 \%$, moderate $\mathrm{BCS}=316.4 \pm$ 13.7 , high $\mathrm{BCS}=323.3 \pm 12.2$; primiparous: low $\mathrm{BCS}$ $=345.6 \pm 24.7$, moderate BCS $=320.7 \pm 14.7$, high $\mathrm{BCS}=326.7 \pm 14.1 \% \mathrm{RI})$. Correlation between milk production and RI was weak $(\mathrm{r}=-0.09 ; P<0.01)$; however, when milk production at the day of timed AI was divided into quartiles, the quartile with the greatest milk production was associated with lower RI in comparison with all other quartiles $(P=0.003$; Table 1 ). Cows that had a corpus luteum at the beginning of the protocol tended to have greater RI at AI (334.5 \pm $5.2 \%$ vs. $320.8 \pm 5.8 \% ; P=0.07)$.

\section{Preovulatory Follicle Diameter}

Preovulatory follicle diameter (mean: $13.4 \pm 2.8$ $\mathrm{mm})$ had no correlation with RI ( $\mathrm{r}=0.02 ; P=0.61)$. The diameter of the preovulatory follicle did not differ among estrus events classified as moderate or strong RI or those that did not express estrus $(P=0.80)$. Follicle diameter was associated with BCS $(P=0.03)$, but not with parity $(P=0.41)$, milk production $(P=0.49)$, or expression of estrus $(P=0.26$; Table 2$)$. Cows with greater concentrations of progesterone at $\mathrm{d} 7 \mathrm{had}$ larger pre-ovulatory follicles at the time of AI $(14.1 \pm 0.2$ vs. $12.3 \pm 0.6 \mathrm{~mm} ; P<0.001$; Table 2).

\section{Concentration of Progesterone in Serum}

Cows with strong RI at timed AI had greater concentration of progesterone in serum at d 7 post-AI compared with those that expressed moderate RI or those that did not show estrus $(3.59 \pm 0.1$ vs. $2.70 \pm$ 0.1 vs. $1.25 \pm 0.2 ; P<0.001)$. When the analysis was restricted to include only animals that had an ovulatory follicle, it was also observed that cows with strong $\mathrm{RI}$ at $\mathrm{AI}$ had a greater concentration of progesterone in serum on $\mathrm{d} 7$ post-AI compared with moderate RI and 
Table 1. Relative increase in physical activity, ovulation rate, and pregnancy/AI according to BCS, parity, and milk production

\begin{tabular}{|c|c|c|c|}
\hline Variable & $\begin{array}{c}\text { Relative increase }^{1} \\
{[\text { mean } \% \pm \text { SEM (no.) }]}\end{array}$ & $\begin{array}{l}\text { Ovulation rate }{ }^{2} \\
[\% \text { (no. } / \text { no. })]\end{array}$ & $\begin{array}{c}\text { Pregnancy } / \mathrm{AI}^{3} \\
[\% \text { (no. } / \text { no. })]\end{array}$ \\
\hline \multicolumn{4}{|l|}{ BCS } \\
\hline$<2.75$ & $300.2 \pm 14.8^{\mathrm{a}}(243)$ & $82.2(88 / 107)$ & $27.5^{\mathrm{a}}(52 / 243)$ \\
\hline$\geq 2.75-3.0$ & $332.1 \pm 9.4^{\mathrm{b}}(523)$ & $85.5(248 / 290)$ & $35.4^{\mathrm{b}}(159 / 523)$ \\
\hline$\geq 3.0$ & $332.1 \pm 9.6^{\mathrm{b}}(640)$ & $87.6(323 / 372)$ & $38.8^{\mathrm{b}}(211 / 640)$ \\
\hline \multicolumn{4}{|l|}{ Parity } \\
\hline Primiparous & $331.1 \pm 12.6^{\mathrm{a}}(576)$ & $87.9(291 / 331)$ & $38.9^{\mathrm{a}}(209 / 576)$ \\
\hline Multiparous & $300.9 \pm 11.1^{\mathrm{b}}(835)$ & $84.3(372 / 442)$ & $28.8^{\mathrm{b}}(214 / 835)$ \\
\hline \multicolumn{4}{|c|}{ Milk production $(\mathrm{kg} / \mathrm{d})$} \\
\hline$\leq 37.5$ & $339.3 \pm 6.4^{\mathrm{a}}(354)$ & $81.5(141 / 173)$ & $27.1(96 / 354)$ \\
\hline$\overline{3} 7.6-44.7$ & $334.9 \pm 7.9^{\mathrm{a}}(353)$ & $87.0(188 / 216)$ & $33.1(117 / 353)$ \\
\hline $44.8-52.1$ & $325.7 \pm 8.0^{\mathrm{a}}(353)$ & $87.6(170 / 191)$ & $29.9(106 / 353)$ \\
\hline$>52.2$ & $298.7 \pm 9.49^{\mathrm{b}}(351)$ & $86.7(164 / 193)$ & $29.8(104 / 351)$ \\
\hline
\end{tabular}

${ }_{\mathrm{a}, \mathrm{b}}$ Different letters indicate differences between variables within the columns $(P<0.05)$.

${ }^{1}$ Relative increase in activity was calculated as the percentage increase in activity at estrus in relation to each cow's own basal activity.

${ }^{2}$ Cows that had a corpus luteum at $\mathrm{d} 7$ after AI.

${ }^{3}$ Number of cows pregnant at $\mathrm{d} 31$ divided by the number of cows inseminated.

those that did not express estrus $(3.48 \pm 0.1$ vs. 3.18 \pm 0.1 vs. $2.13 \pm 0.2 ; P<0.0001)$. Milk production was not correlated with concentration of progesterone at $\mathrm{d}$ $7(\mathrm{r}=-0.01 ; P=0.73)$.

\section{Ovulation Failure}

The overall incidence of ovulation failure was $14.7 \%$ in this study. Cows with strong RI at timed AI had greater ovulation rates when compared with moderate $\mathrm{RI}$ and cows that did not express estrus (94.9 vs. 88.2 vs. $49.5 \%, P<0.001)$. The distribution of ovulation rate according to RI in physical activity at timed $\mathrm{AI}$ is shown in Figure 2. Cows with a corpus luteum present at the beginning of the protocol had greater ovulation rates than those that did not have a corpus luteum (96.6 vs. $88.8 \% ; P<0.01$ ). Ovulation rates were also increased with larger pre-ovulatory follicles (above

Table 2. Means $( \pm \mathrm{SE})$ for preovulatory follicle diameter at the moment of timed $\mathrm{AI}$ and progesterone $(\mathrm{P} 4)$ concentration at d 7 post-AI according to BCS, parity, milk production, P4 concentration at d 7 post-AI, relative increase, and presence of estrus expression (number of animals in the analysis in parentheses)

\begin{tabular}{|c|c|c|}
\hline Variable & $\begin{array}{c}\text { Follicle } \\
\text { diameter }(\mathrm{mm})\end{array}$ & $\begin{array}{c}\text { P4 d } 7 \text { post-AI } \\
\text { (mean ng } / \mathrm{mL} \pm \mathrm{SEM})\end{array}$ \\
\hline \multicolumn{3}{|l|}{$\mathrm{BCS}$} \\
\hline$<2.75$ & $12.6 \pm 0.2^{\mathrm{a}}(79)$ & $2.5 \pm 0.2^{\mathrm{a}}(115)$ \\
\hline$\geq 2.75-3.0$ & $13.6 \pm 0.3^{\mathrm{b}}(201)$ & $3.2 \pm 0.1^{\mathrm{b}}(313)$ \\
\hline$\geq 3.0$ & $13.1 \pm 0.2^{\mathrm{b}}(274)$ & $3.2 \pm 0.1^{\mathrm{b}}(387)$ \\
\hline \multicolumn{3}{|l|}{ Parity } \\
\hline Primiparous & $13.3 \pm 0.4(243)$ & $3.41 \pm 0.1^{\mathrm{a}}(357)$ \\
\hline Multiparous & $13.5 \pm 0.4(315)$ & $2.91 \pm 0.1^{\mathrm{b}}(462)$ \\
\hline \multicolumn{3}{|l|}{ Milk production $(\mathrm{kg})$} \\
\hline$\leq 37.5$ & $13.2 \pm 0.2(155)$ & $3.18 \pm 0.1(245)$ \\
\hline $37.6-44.7$ & $13.4 \pm 0.3(136)$ & $3.11 \pm 0.1(186)$ \\
\hline $44.8-52.1$ & $13.3 \pm 0.3(124)$ & $3.25 \pm 0.1(186)$ \\
\hline$>52.2$ & $13.8 \pm 0.3(143)$ & $2.92 \pm 0.2(163)$ \\
\hline \multicolumn{3}{|c|}{$\mathrm{P} 4$ concentration at $\mathrm{d} 7$ post-AI $(\mathrm{ng} / \mathrm{mL})$} \\
\hline$<1.0$ & $12.3 \pm 0.6^{\mathrm{a}}(111)$ & - \\
\hline $1.0-3.0$ & $12.8 \pm 0.2^{\mathrm{a}}(254)$ & - \\
\hline$>3.0$ & $14.1 \pm 0.2^{\mathrm{b}}(276)$ & - \\
\hline \multicolumn{3}{|c|}{$\begin{array}{l}\text { Automated activity monitor relative } \\
\text { increase }(\%)\end{array}$} \\
\hline Moderate intensity & $13.4 \pm 0.2(188)$ & $2.70 \pm 0.1^{\mathrm{a}}(275)$ \\
\hline Strong intensity & $13.3 \pm 0.1(301)$ & $3.59 \pm 0.2^{\mathrm{b}}(403)$ \\
\hline \multicolumn{3}{|l|}{ Estrus } \\
\hline No estrus & $12.7 \pm 0.6(49)$ & $1.25 \pm 0.3^{\mathrm{a}}(102)$ \\
\hline Estrus & $13.4 \pm 0.1(489)$ & $3.42 \pm 0.2^{\mathrm{b}}(678)$ \\
\hline
\end{tabular}

$\overline{\mathrm{a}, \mathrm{b}}$ Different letters indicate difference between variables within the columns $(P<0.05)$. 


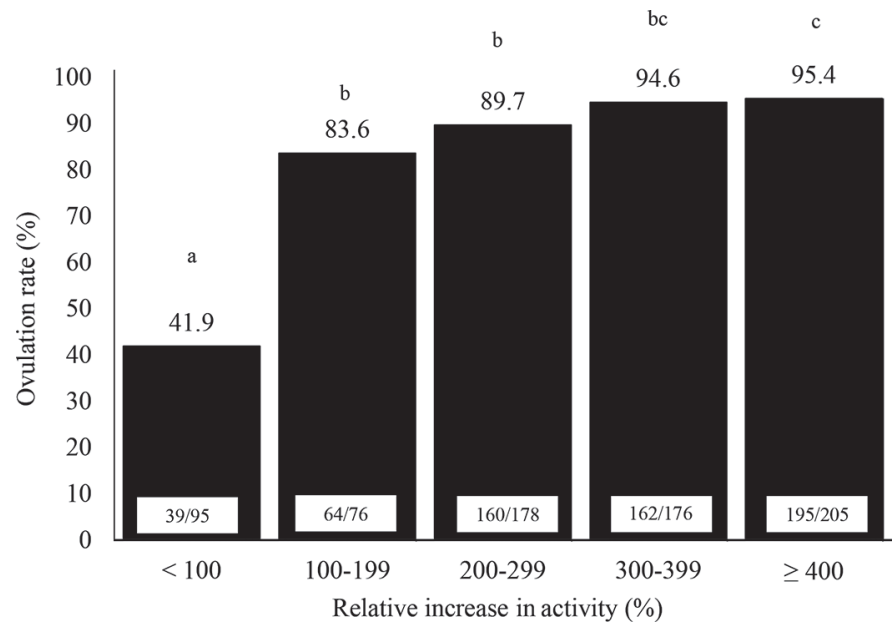

Figure 2. Distribution of ovulation rates (\%) according to relative increase in activity at the moment of timed AI using an automated activity monitor. Different letters $(\mathrm{a}-\mathrm{c})$ indicate difference between variables within the bars $(P<0.05)$.

median diameter) when compared with cows that had smaller pre-ovulatory follicles at timed AI (98.0 vs. 87.4\%; $P<0.01)$.

\section{Factors Affecting Pregnancy per Al and Pregnancy Loss}

Pregnancy per AI was influenced by estrous expression, parity, BCS, presence of a corpus luteum at the beginning of the timed AI protocol, and concentration of progesterone at $\mathrm{d} 7$ post-AI, but not by milk production. Cows that expressed strong RI had greater pregnancy per AI compared with those with moderate RI or those that did not express estrus at timed AI (35.1 vs. 27.3 vs. $6.2 \% ; P<0.01)$. Cows that expressed strong RI still had greater pregnancy per AI compared with those with moderate RI and those that did not express estrus when only cows that had an ovulatory follicle were considered (45.1 vs. 34.8 vs. $5.5 \%, P<0.001$ ). The distribution of pregnancy per AI according to RI at timed AI is shown in Figure 3. Furthermore, estrous expression also affected pregnancy loss. Cows that did not express estrus or had moderate RI at the moment of timed AI had greater pregnancy loss when compared with animals that had strong RI (19.2 vs. 21.7 vs. $13.9 \%, P=0.04)$. The distribution of pregnancy losses according to RI at timed AI is summarized in Figure 4.

Parity and BCS were associated with pregnancy per AI. Multiparous cows had reduced pregnancy per AI compared with primiparous cows $(28.8$ vs. $38.9 \%$; $P$ $<0.01)$ and cows with high and moderate BCS had greater pregnancy per AI than cows with low BCS (38.8 vs. 32.9 vs. $22.4 \% ; P=0.003$ ). Cows bearing a corpus luteum at the beginning of the protocol $(\mathrm{d}-11)$ tended to have greater pregnancy per AI than those that did not (32.0 vs. $27.8 \% ; P=0.09)$. Cows with greater concentrations of progesterone at $\mathrm{d} 7$ post-AI had a greater pregnancy per AI compared with cows that had lower concentrations $(>3.0 \mathrm{ng} / \mathrm{mL}=42.6 \%$ vs. $\geq 1.0$ and $\leq 3.0 \mathrm{ng} / \mathrm{mL}=37.2 \%$ vs. $<1.0 \mathrm{ng} / \mathrm{mL}$ $=19.6 \% ; P<0.01)$. Milk production had no effect on pregnancy per AI $(P=0.37)$.

\section{DISCUSSION}

The goal of our study was to evaluate whether the expression of estrus, detected by AAM, at the moment of timed AI would affect pregnancy per AI, pregnancy loss, and parameters of ovarian function associated with fertility. Cows categorized as strong RI physical activity at timed AI had greater pregnancy per AI and

A)

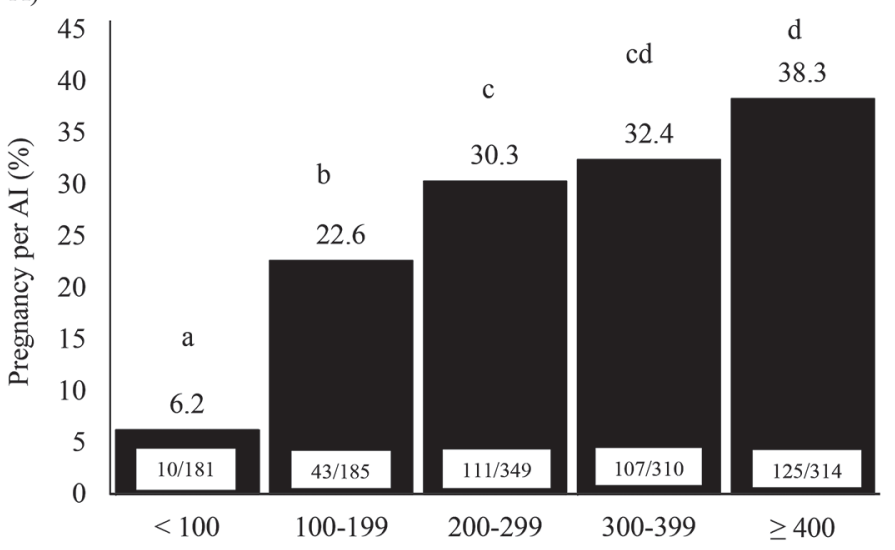

B)

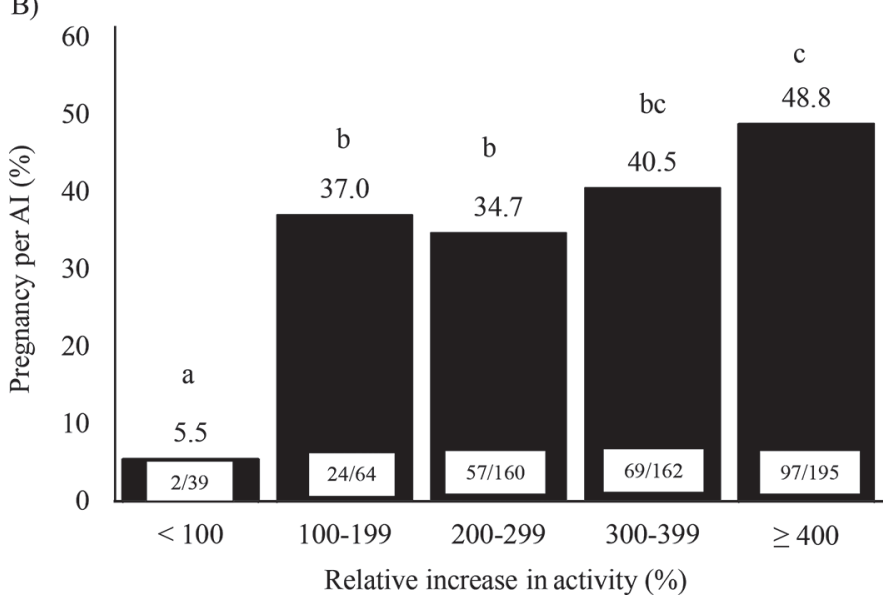

Figure 3. Distribution of pregnancy per AI (\%) of all insemination events according to relative increase in activity at timed AI detected by an automated activity monitor (panel A) and considering only cows that had an ovulatory follicle (panel B). Different letters (a-d) indicate difference between variables within the bars $(P<0.05)$. 
A)

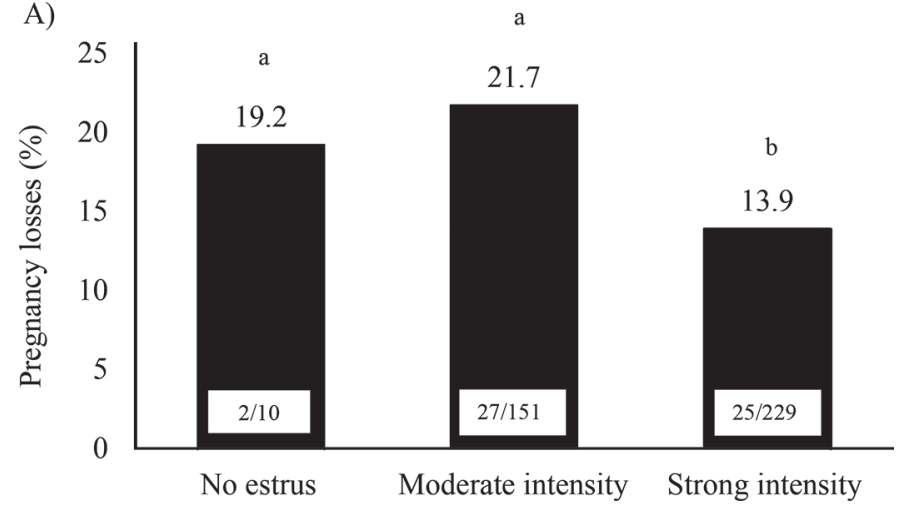

Classification of peak of activity ( $\%$ relative increase)

B)

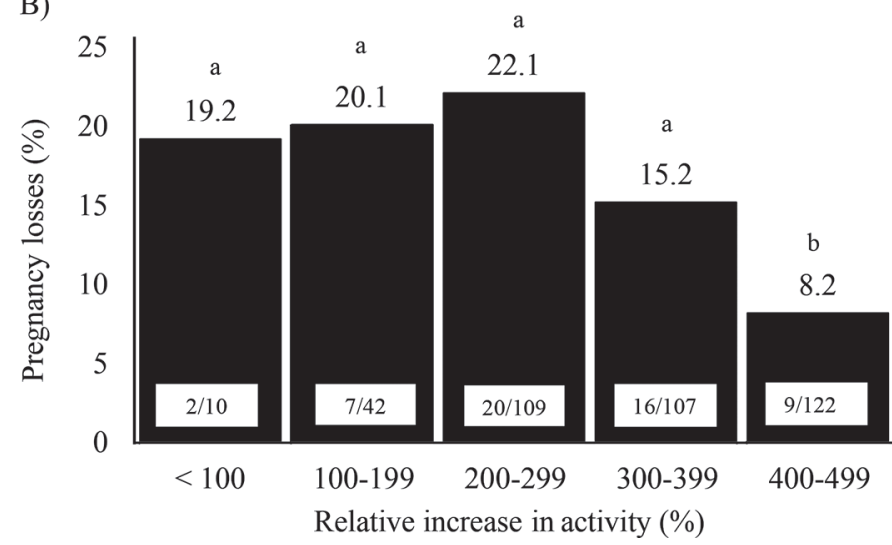

Figure 4. Pregnancy losses (\%) according to categories of relative increase in physical activity at timed AI: no estrus $(<100 \%)$, moderate intensity (100-299\% relative increase), and strong intensity $(\geq 300 \%$ relative increase) as detected by an automated activity monitor (panel $\mathrm{A} ; P=0.03)$ and distribution of pregnancy losses (\%) according to relative increase in physical activity at timed AI detected by an automated activity monitor (panel B). Different letters $(\mathrm{a}, \mathrm{b})$ indicate difference between variables within the bars $(P<0.05)$.

decreased pregnancy loss compared with those cows expressing moderate RI and those that did not express estrus at timed AI. This pattern remained the same when only cows that successfully ovulated after timed AI were included in the analysis. Estrous expression at the moment of timed AI could potentially be used as a reproduction strategy tool that adds predictive information about a specific breeding and assists in decision-making strategies at the farm level. Future studies might include the use of such information in breeding programs of greater risk or value, such as the use of sex-biased semen and embryo transfer.

The use of timed AI in this study allowed for the evaluation of potential mechanisms that may be producing estrus-induced differences in fertility that have previously been reported with spontaneous estrus events (Madureira et al., 2015; Burnett et al., 2017,
2018; Polsky et al., 2017; Silper et al., 2017). We expected that (1) cows displaying estrus at the moment of AI would have greater pregnancy per AI than those that did not display estrus (Pereira et al., 2014), and (2) cows displaying a strong RI in physical activity at timed AI would also have greater fertility (Madureira et al., 2015; Burnett et al., 2017, 2018; Polsky et al., 2017; Silper et al., 2017). Specifically, previous studies from our laboratory already demonstrated the significant effect of strong RI of estrus on fertility, but those studies used mostly spontaneous estrus events. The limitation of using spontaneous estrus events to study possible mechanisms affecting fertility is the lack of control over the ovarian cycle preceding the estrus event, which could potentially affect subsequent estrous expression (Denis-Robichaud et al., 2018a). In agreement with the present study, Pereira et al. (2016) reported that the display of estrous behavior at timed AI was associated with a reduction in pregnancy loss, but the variation in intensity of estrous expression was not explored. To the best of our knowledge, this is the first report describing the effect of the intensity of estrous expression following a timed AI protocol on the ability of dairy cattle to sustain pregnancy, as opposed to using only spontaneous estrus events. The timed AI protocol was aimed at synchronizing a follicular wave and corpus luteum function, producing an optimal endocrine environment with a pre-ovulatory follicle and synchronization of ovulation (Wiltbank et al., 2011). It has been suggested that timed AI can potentially improve fertility by modulating the pre-ovulatory follicle and oocyte quality (Cerri et al., 2009) as well as the uterine environment (Cerri et al., 2011a). This could have implications on how estrous behavior intensity affects fertility compared with what has been observed in spontaneous estrus events.

The high concentrations and long exposure to estradiol during proestrus and estrus result in the expression of estrogen-dependent glycoproteins from the oviduct, which have been implicated in changes in sperm transport, the uterine environment, and oocyte fertilization (Buhi, 2002). Evidence indicates that the circulating concentration of estradiol has a positive correlation with intensity of behavioral estrus, assessed by standing to be mounted behavior (Lopez et al., 2004). Plasma concentration of estradiol, however, has been reported to be not correlated (Aungier et al., 2015) or weakly correlated (Madureira et al., 2015; Silper et al., 2015a) with walking activity detected by AAM. Reames et al. (2011) evaluated the relationship between infused estradiol, the occurrence of behavioral estrus and the LH surge in ovariectomized cows. The authors reported that with low doses of estradiol infusions some cows did 
not display estrus, but still had an LH surge, suggesting that the center responsible for estrous behavior might have a different center activation threshold of circulating estradiol compared with the center responsible for the LH surge. Thus, cows that ovulated but did not express estrus may have achieved the threshold of circulating concentrations of estradiol that are needed to induce the GnRH surge and subsequently the LH surge, but insufficient to induce estrous behaviors. In this study cows that displayed estrus, induced by estradiol cypionate, indeed had significantly better fertility than those that did not show estrus. This result agrees with a previous study (42.6 vs. $21.1 \%$; Cerri et al., 2004) using a different ovulation synchronization (Heatsynch), but that also used estradiol cypionate to induce ovulation. Reasons for this large difference was tightly correlated with ovulation rates, which are much lower for cows that did not display estrus.

In spite of the clear differences in fertility and ovarian function expected between cows that displayed estrus compared with those that did not, it was unclear if the same tendency would be observed in cows displaying different intensity of estrus (strong RI vs. moderate RI) in estradiol cypionate induced events. The pre-ovulatory follicle diameter was not correlated with RI and did not differ between estrus events classified as having strong or moderate RI in physical activity. Concentrations of estradiol- $17 \beta$ produced by the preovulatory follicle and preceding diestrus concentrations of progesterone are involved in triggering the expression of estrous behavior (Allrich, 1994; Forde et al., 2011; Reames et al., 2011). Some studies have shown that there is no correlation between pre-ovulatory follicle diameter and plasma estradiol in lactating dairy cattle (Sartori et al., 2004; Madureira et al., 2015). Although estradiol concentration at onset of estrus has been observed to be approximately $1 \mathrm{pg} / \mathrm{mL}$ greater in cows expressing high intensity estrus (Madureira et al., 2015), correlation between estradiol concentration in serum and estrus activity levels is surprisingly weak (Aungier et al., 2015; Madureira et al., 2015). Progesterone concentration in serum was not measured at the beginning of the timed AI protocol in this experiment, but cows that had a corpus luteum at the start of the timed AI protocol were more likely to have a high intensity estrus at the moment of AI and also more likely to ovulate. In addition, concentrations of progesterone $7 \mathrm{~d}$ after AI were greater in cows displaying strong RI estrus at AI than those that displayed estrus of lower intensity. Collectively, the results from the ovarian function suggest that progesterone is a key modulator that led to estrous expression of higher intensity and greater fertility. Increases in progesterone concentration post-AI have been reported to sustain embryo and fetal development (Bisinotto et al., 2010a), which may be caused by the changes in the progesterone receptor profile within the endometrium (Lonergan, 2011). This relationship could have contributed to the increase in pregnancy per AI and reduction in pregnancy loss found in cows with strong RI in this study. Along with the same rationale of progesterone as the main driver for strong RI estrus events and greater fertility, the concentration of progesterone at AI, which was not evaluated in this study, could be another possible factor associating estrous expression and fertility. Increases in circulating progesterone concentration at AI have been related to inadequate luteolysis and reductions in fertility in dairy cattle (Wiltbank et al., 2012). Souza et al. (2007) reported that progesterone concentration $48 \mathrm{~h}$ after $\mathrm{PGF}_{2 \alpha}$ treatment above $0.5 \mathrm{ng} / \mathrm{mL}$ reduced pregnancy per AI by 50\%. Similarly, Pereira et al. (2013b) used the same synchronization protocol as the current study and found that concentrations of progesterone near AI above $0.1 \mathrm{ng} / \mathrm{mL}$ resulted in decreased fertility $(\leq 0.09 \mathrm{ng} / \mathrm{mL}=34.1 \%$ vs. $\geq 0.1 \mathrm{ng} / \mathrm{mL}=20.8 \%)$. Progesterone can potentially alter oocyte transport in the oviduct by affecting contractility (Hunter, 2005), as well as reducing embryo development (Silva et al., 1999), which can lead to decreased fertility.

The differences in ovulation rates between strong and moderate RI, although significantly different $(P$ $<0.05$ ), are more modest (94.9 vs. $88.2 \%$ ). The differences in ovulation rate found in this study do agree with the findings from Burnett et al. (2018), who used only spontaneous estrus events, and may at least partially explain the fertility outcomes. Nevertheless, when only cows had an ovulatory follicle were analyzed, the same association of strong RI resulting in higher pregnancy per AI was found. The fact that estradiol cypionate was used to induce ovulation and that concentration of estradiol was likely elevated in both groups, raises the possibility that estrogen receptors might also be key to explain the differences in fertility between strong and moderate RI groups found in this study. Cows might have a large individual variation in the ability to express estrogen receptors in the endometrium and in the hypothalamus. Probably some cows or some estrus events are more likely to translate circulating estradiol concentrations into optimal expression of estrus and adequate uterine environment for embryo development. To some extent, the LH surge is another possible factor to explain the results in fertility found herein between cows that displayed strong and moderate RI estruses, but further studies are necessary to confirm this hypothesis.

Parity influenced estrus intensity, as multiparous cows expressed lower RI at the moment of AI. This is in agreement with other studies (López-Gatius et al., 
2005; Madureira et al., 2015) using spontaneous estrus and different AAM systems. López-Gatius et al. (2005) reported that for each additional lactation, walking activity at estrus was reduced by $21.4 \%$. Contrary to these results, Walker et al. (1996) described that duration of estrus was shorter for primiparous than for multiparous lactating dairy cows. Additionally, BCS at estrus tended to affect RI, as cows with lower BCS tended to have lower estrus intensity. The BCS has been consistently shown to be one of the strongest factors associated with a RI in physical activity and duration at estrus detected by AAM (Løvendahl and Chagunda, 2010; Madureira et al., 2015; Silper et al., 2017; Burnett et al., 2017). Poor BCS has been associated with delayed display of estrus postcalving, longer interval to first service and to conception, and reduced pregnancy to first AI (Roche et al., 2009). The transition period in dairy cows has an important role in reproductive success and likely affects the intensity of estrous expression. After calving, cows experience negative energy balance, which has negative effects on fertility through metabolic and endocrine modulations in the liver, ovary, and functioning of the uterus (Wathes et al., 2007b). Cows that experience an intense negative energy balance (lower insulin, glucose, and IGF-I) have reduced LH pulse frequency, which decreases the synthesis of estradiol by the preovulatory follicle (Butler, 2003). The IGF-1 in particular is a growth factor essential to follicular growth and estradiol synthesis (Garnsworthy et al., 2008) and has functional interactions with estrous cycles and sexual behavior (Woelders et al., 2014).

No correlation was observed between milk production and RI of activity; however, when categorized by quartiles, greater milk production was associated with lower RI. The increased individual milk production has been negatively associated with standing to be mounted at estrus (Lopez et al., 2004; Rivera et al., 2010), which overall agrees with the findings from this study. A possible cause for the decrease in estrus-related behaviors might be the decrease in ovarian steroid concentrations, mainly progesterone, which occurs in response to increased hepatic blood flow and steroid clearance in lactating dairy cattle (Sangsritavong et al., 2002; Vasconcelos et al., 2003).

\section{CONCLUSIONS}

Greater estrous expression at timed AI improved ovulation rates and pregnancy per AI, and reduced pregnancy loss. These results provide further evidence that measurements of estrous expression, even in timed AI programs, might be a reliable predictor of fertility and could be used as a tool to assist in the decision mak- ing of reproduction strategies at the farm level. Cows that had greater estrous expression also had greater circulating concentration of progesterone $7 \mathrm{~d}$ post-AI, providing evidence of improved ovarian function following those high intensity estrus events. The improvement in fertility with increased estrous expression was also linked with reduced pregnancy loss, which further supports the notion that the endometrium environment is significantly affected by the mechanisms that cause greater intensity of estrus.

\section{ACKNOWLEDGMENTS}

This study was supported by a contribution from the Dairy Research Cluster Initiative II (Dairy Farmers of Canada, Agriculture and Agri-Food Canada, the Canadian Dairy Network, and the Canadian Dairy Commission; Ottawa, Canada). Partial funding was also provided by the Natural Sciences and Engineering Research Council, Discovery Grant (Ottawa, Canada). We are thankful to Fazenda Colorado (Araras, Brazil) and their farm personnel for contributing with this research project as well as students, interns, and operational support from Conapec Jr., Sao Paulo State University, Botucatu, Brazil.

\section{REFERENCES}

Allrich, R. D. 1994. Endocrine and neural control of estrus in dairy cows. J. Dairy Sci. 77:2738-2744.

Aungier, S. P. M., J. F. Roche, P. Duffy, S. Scully, and M. A. Crowe. 2015. The relationship between activity clusters detected by an automatic activity monitor and endocrine changes during the periestrus period in lactating dairy cows. J. Dairy Sci. 98:1666-1684.

Bisinotto, R. S., E. S. Ribeiro, L. T. Martins, R. S. Marsola, L. F. Greco, M. G. Favoreto, C. A. Risco, W. W. Thatcher, and J. E. Santos. 2010a. Effect of interval between induction of ovulation and artificial insemination (AI) and supplemental progesterone for resynchronization on fertility of dairy cows subjected to a 5-d timed AI program. J. Dairy Sci. 93:5798-5808.

Buhi, W. C. 2002. Characterization and biological roles of oviductspecific, oestrogen-dependent glycoprotein. Reproduction 123:355362.

Burnett, T. A., A. M. L. Madureira, B. F. Silper, A. C. C. Fernandes, and R. L. A. Cerri. 2017. Effects of integrating an automated activity monitor into a first postpartum artificial insemination program and health related risk-factors on reproductive performance in lactating dairy cows. J. Dairy Sci. 100:5005-5018.

Burnett, T. A., L. Polsky, M. Kaur, and R. L. A. Cerri. 2018. Effect of estrous expression on ovulation times and ovulation failure of Holstein dairy cows. J. Dairy Sci. 101:11310-11320. https://doi .org/10.3168/jds.2018-15151.

Butler, W. R. 2003. Energy balance relationships with follicular development, ovulation and fertility in postpartum dairy cows. Livest. Prod. Sci. 83:211-218.

Cerri, R. L., H. M. Rutigliano, R. C. Chebel, and J. E. P. Santos. 2009. Period of dominance of the ovulatory follicle influences embryo quality in lactating dairy cows. Reproduction 137:813-823.

Cerri, R. L., J. E. Santos, S. O. Juchem, K. N. Galvao, and R. C. Chebel. 2004. Timed artificial insemination with estradiol cypi- 
onate or insemination at estrus in high-producing dairy cows. J. Dairy Sci. 87:3704-3715.

Cerri, R. L. A., R. C. Chebel, F. Rivera, C. D. Narciso, R. A. Oliveira, M. Amstalden, G. M. Baez-Sandoval, L. J. Oliveira, W. W. Thatcher, and J. E. P. Santos. 2011a. Concentration of progesterone during the development of the ovulatory follicle: II. Ovarian and uterine responses. J. Dairy Sci. 94:3352-3365.

Chebel, R. C., M. J. Al-Hassan, P. M. Fricke, J. E. P. Santos, J. R. Lima, C. A. Martel, J. S. Stevenson, R. Garcia, and R. L. Ax. 2010. Supplementation of progesterone via controlled internal drug release inserts during ovulation synchronization protocols in lactating dairy cows. J. Dairy Sci. 93:922-931.

Davoodi, S., R. F. Cooke, A. C. C. Fernandes, B. I. Cappellozza, J. L. M. Vasconcelos, and R. L. A. Cerri. 2016. Expression of estrus modifies the gene expression profile in reproductive tissues on Day 19 of gestation in beef cows. Theriogenology 85:645-655.

Denis-Robichaud, J., R. L. A. Cerri, A. Jones-Bitton, and S. J. LeBlanc. 2018b. Performance of automated activity monitoring systems used in combination with timed artificial insemination compared to timed artificial insemination only in early lactation in dairy cows. J. Dairy Sci. 101:624-636.

Denis-Robichaud, J., S. J. LeBlanc, A. Jones-Bitton, B. F. Silper, and R. L. A. Cerri. 2018a. Pilot study to evaluate the association between the length of the luteal phase and estrous activity detected by automated activity monitoring in dairy cows. Front. Vet. Sci. 5:210. https://doi.org/10.3389/fvets.2018.00210.

Dobson, H., S. L. Walker, M. J. Morris, J. E. Routly, and R. F. Smith. 2008. Why is it getting more difficult to successfully artificially inseminate dairy cows? Animal 2:1104-1111.

Edmonson, A. J., I. J. Lean, L. D. Weaver, T. Farver, and G. Webster. 1989. A body condition score chart for Holstein dairy cows. J. Dairy Sci. 72:68-78.

FASS. 1999. Guide for the care and use of agricultural animals in agricultural research and teaching. FASS, Champaign, IL.

Forde, N., M. E. Beltman, G. B. Duffy, P. Duffy, J. P. Mehta, P. O'Gaora, J. F. Roche, P. Lonergan, and M. A. Crowe. 2011. Changes in the endometrial transcriptome during the bovine estrous cycle: Effect of low circulating progesterone and consequences for conceptus elongation. Biol. Reprod. 84:266-278.

Garnsworthy, P. C., K. D. Sinclair, and R. Webb. 2008. Integration of physiological mechanisms that influence fertility in dairy cows. Animal 2:1144-1152.

Hunter, R. H. F. 2005. The Fallopian tubes in domestic mammals: How vital is their physiological activity? Reprod. Nutr. Dev. 45:281-290.

Lonergan, P. 2011. Influence of progesterone on oocyte quality and embryo development in cows. Theriogenology 76:1594-1601.

Lopez, H., Z. Wu, L. D. Satter, and M. C. Wiltbank. 2004. Effect of dietary phosphorus concentration on estrous behaviour of lactating dairy cows. Theriogenology 61:437-445.

López-Gatius, F., P. Santolaria, I. Mundet, and J. L. Yániz. 2005. Walking activity at estrus and subsequent fertility in dairy cows. Theriogenology 63:1419-1429.

Løvendahl,, P., and G. G. Chagunda. 2010. On the use of physical activity monitoring for estrus detection in dairy cows. J. Dairy Sci. 93:249-259.

Madureira, A. M. L., B. F. Silper, T. A. Burnett, L. Polsky, L. H. Cruppe, D. M. Veira, J. L. M. Vasconcelos, and R. L. A. Cerri. 2015. Factors affecting expression of estrus measured by activity monitors and conception risk of lactating dairy cows. J. Dairy Sci. 98:7003-7014.

Martin, J. L., K. A. Vonnahme, D. C. Adams, G. P. Lardy, and R. N. Funston. 2007. Effects of dam nutrition on growth and reproductive performance of heifer calves. J. Anim. Sci. 85:841-847.

Neves, R. C., K. E. Leslie, J. S. Walton, and S. J. LeBlanc. 2012. Reproductive performance with an automated activity monitoring system versus a synchronized breeding program. J. Dairy Sci. 95:5683-5693.

NRC. 2001. Nutrient Requirements for Dairy Cattle. National Academy of Sciences, Washington, DC.
Pereira, M. H., A. D. Rodrigues, R. J. De Carvalho, M. C. Wiltbank, and J. L. Vasconcelos. 2014. Increasing length of an estradiol and progesterone timed artificial insemination protocol decreases pregnancy losses in lactating dairy cows. J. Dairy Sci. 97:1454-1464.

Pereira, M. H., C. P. Sanches, T. G. Guida, A. D. Rodrigues, F. L. Aragon, M. B. Veras, P. T. Borges, M. C. Wiltbank, and J. L. Vasconcelos. 2013b. Timing of prostaglandin F2 $\alpha$ treatment in an estrogen-based protocol for timed artificial insemination or timed embryo transfer in lactating dairy cows. J. Dairy Sci. 96:28372846.

Pereira, M. H., M. C. Wiltbank, L. F. Barbosa, W. M. Costa, M. A. Carvalho, and J. L. Vasconcelos. 2015. Effect of adding a gonadotropin-releasing-hormone treatment at the beginning and a second prostaglandin F2 $\alpha$ treatment at the end of an estradiol-based protocol for timed artificial insemination in lactating dairy cows during cool or hot seasons of the year. J. Dairy Sci. 98:947-959.

Pereira, M. H. C., M. C. Wiltbank, and J. L. M. Vasconcelos. 2016. Expression of estrus improves fertility and decreases pregnancy losses in lactating dairy cows that receive artificial insemination or embryo transfer. J. Dairy Sci. 99:2237-2247.

Polsky, L. B., A. M. L. Madureira, E. L. Drago, S. Soriano, A. F. Sica, J. L. M. Vasconcelos, and R. L. A. Cerri. 2017. Associations between vaginal temperature and induced estrus expression and fertility in lactating Holstein cows. J. Dairy Sci. 100:8590-8601.

Pursley, J. R., M. O. Mee, and M. C. Wiltbank. 1995. Synchronization of ovulation in dairy cows using PGF2a and GnRH. Theriogenology 44:915-923.

Reames, P. S., T. B. Hatler, S. H. Hayes, D. L. Ray, and W. J. Silvia. 2011. Differential regulation of estrous behavior and luteinizing hormone secretion by estradiol-17 $\beta$ in ovariectomized dairy cows. Theriogenology 75:233-240.

Reis, M. M., R. F. Cooke, B. I. Cappellozza, R. S. Marques, T. A. Guarnieri Filho, M. C. Rodrigues, J. S. Bradley, C. J. Mueller, D. H. Keisler, S. E. Johnson, and D. W. Bohnert. 2015. Creep-feeding to stimulate metabolic imprinting in nursing beef heifers: Impacts on heifer growth, reproductive, and physiological parameters. Animal 9:1500-1508.

Rivera, F., C. Narciso, R. Oliveira, R. L. A. Cerri, A. Correa-Calderón, R. C. Chebel, and J. E. P. Santos. 2010. Effect of bovine somatotropin $(500 \mathrm{mg}$ ) administered at ten-day intervals on ovulatory responses, expression of estrus, and fertility in dairy cows. J. Dairy Sci. 93:1500-1510.

Roche, J. R., N. C. Friggens, J. K. Kay, M. W. Fisher, K. J. Stafford, and D. P. Berry. 2009. Invited review: Body condition score and its association with dairy cow productivity, health, and welfare. J. Dairy Sci. 92:5769-5801.

Roelofs, J., F. López-Gatius, R. H. F. Hunter, F. J. C. M. van Eerdenburg, and C. Hanzen. 2010. When is a cow in estrus? Clinical and practical aspects. Theriogenology 74:327-344. https://doi.org/10 $.1016 / j$.theriogenology.2010.02.016.

Sangsritavong, S., D. K. Combs, R. Sartori, and M. C. Wiltbank. 2002. High feed intake increases blood flow and metabolism of progesterone and estradiol-17 $\beta$ in dairy cattle. J. Dairy Sci. 85:2831-2842.

Sartori, R., J. M. Haughian, R. D. Shaver, G. J. M. Rosa, and M. C. Wiltbank. 2004. Comparison of ovarian function and circulating steroids in estrous cycles of Holstein heifers and lactating cows. J. Dairy Sci. 87:905-920. https://doi.org/10.3168/jds.S0022 -0302(04)73235-X.

Silper, B. F., A. M. L. Madureira, L. B. Polsky, S. Soriano, A. F. Sica, J. L. M. Vasconcelos, and R. L. A. Cerri. 2017. Daily lying behavior of lactating Holstein cows during an estrus synchronization protocol and its associations with fertility. J. Dairy Sci. 100:8484-8495.

Silper, B. F., I. Robles, A. M. L. Madureira, T. A. Burnett, M. M. Reis, A. M. de Passillé, J. Rushen, and R. L. A. Cerri. 2015a. Automated and visual measurements of estrous behavior and their sources of variation in Holstein heifers I: Walking activity and behavior frequency. Theriogenology 84:312-320.

Silva, C. C., N. P. Groome, and P. G. Knight. 1999. Demonstration of a suppressive effect of inhibin alphasubunit on the developmental 
competence of in vitro matured bovine oocytes. J. Reprod. Fertil. 115:381-388.

Souza, A. H., A. Gümen, E. P. Silva, A. P. Cunha, J. N. Guenther, C. M. Peto, D. Z. Caraviello, and M. C. Wiltbank. 2007. Supplementation with estradiol-17beta before the last gonadotropin-releasing hormone injection of the Ovsynch protocol in lactating dairy cows. J. Dairy Sci. 90:4623-4634.

Stevenson, J. S., and A. P. Phatak. 2005. Inseminations of estrus induced by presynchronization before application of synchronized estrus and ovulation. J. Dairy Sci. 88:399-405.

Vasconcelos, J. L. M., S. Sangsritavong, S. J. Tsai, and M. C. Wiltbank. 2003. Acute reduction in serum progesterone concentrations after feed intake in dairy cows. Theriogenology 60:795-807.

Walker, W. L., R. L. Nebel, and M. L. McGilliard. 1996. Time of ovulation relative to mounting activity in dairy cattle. J. Dairy Sci. 79:1555-1561.
Wathes, D. C., D. R. Abayasekara, and R. J. Aitken. 2007b. Polyunsaturated fatty acids in male and female reproduction. Biol. Reprod. 77:190-201. https://doi.org/10.1095/biolreprod.107.060558.

Wiltbank, M. C., R. Sartori, M. M. Herlihy, J. L. Vasconcelos, A. B. Nascimento, A. H. Souza, H. Ayres, A. P. Cunha, A. Keskin, J. N. Guenther, and A. Gumen. 2011. Managing the dominant follicle in lactating dairy cows. Theriogenology 76:1568-1582.

Wiltbank, M. C., A. H. Souza, J. O. Giordano, A. B. Nascimento, J. L. M. Vasconcelos, M. H. C. Pereira, P. M. Fricke, R. S. Surjus, F. C. S. Zinsly, P. D. Carvalho, R. W. Bender, and R. Sartori. 2012. Positive and negative effects of progesterone during timed AI protocols in lactating dairy cattle. Anim. Reprod. 9:231-241.

Woelders, H., T. Van der Lende, A. Kommadath, M. Te Pas, M. Smits, and L. Kaal. 2014. Central genomic regulation of the expression of oestrous behaviour in dairy cows: A review. Animal 8:754-764. https://doi.org/10.1017/S1751731114000342. 